\title{
Epidemiology of Eye Disease in the Elderly
}

\author{
L. HYMAN \\ New York, USA
}

\begin{abstract}
Summary
Most of the estimated 40 million blind individuals in the world are in the older age groups. Data on blindness and visual impairment are primarily from blindness registries and prevalence surveys in different countries throughout the world. The quality of these data vary tremendously from one country to another, and comparability of the results from different studies is difficult. However, all studies indicate an increase in the prevalence of visual loss and blindness with increasing age. Cataract is the most prevalent eye disease in the world and is a major cause of visual loss in developing as well as in developed countries. Other major eye diseases in the elderly include age related macular degeneration, glaucoma, and diabetic retinopathy. A number of risk factors have been suggested for cataract, age related macular degeneration, and glaucoma, yet few have been well established. Certain factors for these conditions are similar, including age, hypertension, prolonged exposure to sunlight, and nutritional factors such as Vitamin E. Epidemiologic studies are needed to define the risk factors for these different eye diseases with the goal of decreasing risk of disease and possible disease prevention, as well as developing better estimates of the magnitude of the problems of visual loss and eye diseases in the elderly.
\end{abstract}

The total number of blind individuals throughout the world has been estimated to be as high as 40 million. ${ }^{1}$ In both developing and developed countries the majority of these blind individuals are in the older age groups. With increasing numbers of individuals now reaching the age of 60 years and older, the numbers of visually impaired persons will also increase. This will create needs for additional services, programmes, and treatment for the visually impaired. Therefore, it is important to determine the magnitude of the problem in different countries, as well as globally. Identification of the specific causes of visual loss and blindness is essential in order to develop appropriate treatment, rehabilitation, and service programmes. In addition, identification of risk factors for the major causes of blindness is needed to develop measures for prevention of visual impairment.

The objectives of this discussion are to:

(1) define the magnitude of visual impairment, visual loss, and blindness in the elderly;

(2) describe the epidemiologic characteristics of the leading causes of eye disease in the elderly (e.g. cataracts, age related macular degeneration (AMD), glaucoma, diabetic retinopathy);

(3) discuss possible risk factors for cataracts, age related macular degeneration and glaucoma; and

From Department of Community and Preventive Medicine, State University of New York at Stony Brook, New York, USA.

Correspondence to: Leslie Hyman, Ph.D., Division of Epidemiology, Department of Community and Preventive Medicine, School of Medicine, Health Sciences Center, 3L 099, State University of New York at Stony Brook, Stony Brook, New York 11794. 
Table I. Rate of visual impairment* by age and sex, National Health Interview Survey, $1983^{10}$

\begin{tabular}{lccc}
\hline & \multicolumn{3}{c}{ Ratel1,000 } \\
\cline { 2 - 4 } Age & $\begin{array}{c}\text { Males and } \\
\text { females }\end{array}$ & Males & Females \\
\hline $45-64$ & 49.7 & 63.1 & 37.6 \\
$65-74$ & 63.3 & 69.0 & 58.9 \\
$\geqslant 75$ & 138.9 & 138.7 & 139.1 \\
\hline
\end{tabular}

* Visual impairment $=$ Blindness in one or both eyes or any other trouble seeing even when wearing glasses.

(4) discuss possible contributions of epidemiology towards addressing problems of eye disease in the elderly (e.g. prevention, treatment).

\section{Prevalence of Visual Impairment and Blindness}

Estimates for the prevalence of severe visual impairmnent and blindness can be obtained from blindness registries. The major published sources of blindness statistics have been blindness registries in England and Wales, ${ }^{2}$ Oxford,${ }^{3}$ Scotland, ${ }^{4}$ the United States, ${ }^{5}$ and Canada. ${ }^{6}$ Other estimates have been developed in Nepal ${ }^{7}$ and other Asian and African nations. ${ }^{8,9}$ The quality and completeness of these data vary significantly from one country to another. Comparability of the results from

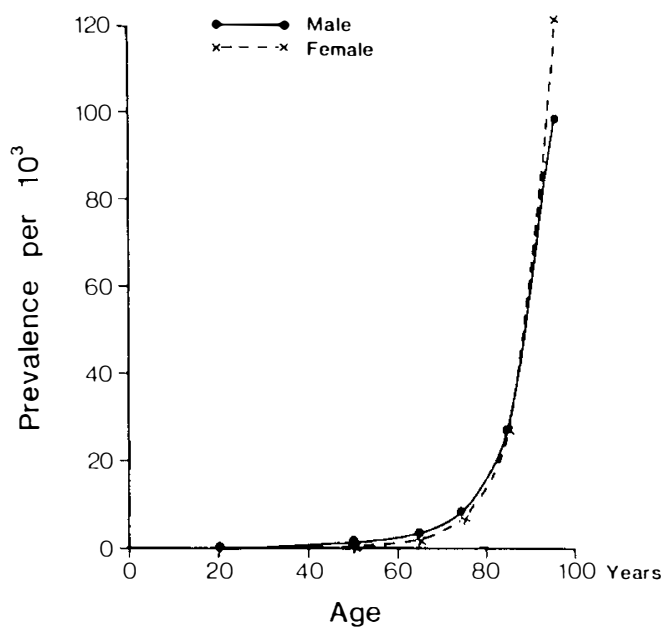

Fig. 1. Registered blind in Oxford, 1966 (Caird, unpublished). ${ }^{3}$ different registries is difficult due mainly to variability in:

(1) definitions of blindness;

(2) regulations for blindness registration;

(3) cultural or socioeconomic factors influencing reasons for registration.

Although there are limitations to the quality of the data obtained from different blindness registries, these data consistently demonstrate a significant increase in blindness with increasing age. Figure 1 clearly indicates a dramatic increase in the prevalence rate per 1,000 of those individuals who registered as blind in Oxford, England in 1966. According to these data, the prevalence of blindness registration increases approximately 20 times between the ages of 65 and 90 , with the blindness rate increasing from approximately 0.5 per cent at age 65 to as high as 10 per cent over the age of 90 . These rates are similar for both males and females. ${ }^{3}$

A second source of data on the prevalence of visual impairment, blindness, and eye disease in the elderly is prevalence studies. Three major population based studies published in recent years have provided information on the prevalence of visual impairment and vision loss and on the causes of vision loss in the United States. They are known as the National Health Interview Survey (HIS), ${ }^{10}$ the Framingham Eye Study (FES), ${ }^{11}$ and the National Health and Nutrition Examination Survey (NHANES), ${ }^{12}$ and will be discussed later. Prevalence studies that have been published from other countries include one in Iceland on legal blindness, ${ }^{13}$ one in New Zealand on ocular disease in individuals 65 years and older, ${ }^{14}$ and one in Nepal on blindness and cataract prevalence. ${ }^{7}$ As with the blindness registries, findings from these different studies are not usually comparable to one another because of different definitions of visual impairment and specific eye conditions and different methods of evaluating vision loss.

Data from the HIS, 1983 are presented in Table I. This survey is an ongoing cross-sectional household interview survey that started in 1957 on a sample of the civilian, non-institutionalised United States population. It provides national data on the prevalence of chronic conditions and impairments as well as 
Table II. Frequency of good and poor visual acuity by age and sex, Framingham eye study 1973-197511

\begin{tabular}{lccc}
\hline & \multicolumn{3}{c}{ Age (years) } \\
\cline { 2 - 4 } & $<65$ & $65-74$ & $\geqslant 75$ \\
& $M+F$ & $M+F$ & $M+F$ \\
Visual acuity & $(N=1,382)$ & $(N=853)$ & $(N=395)$ \\
& $\%$ & $\%$ & $\%$ \\
$20 / 20-20 / 25$ & 91.2 & 88.7 & 71.9 \\
$20 / 200$ or worse & 0.1 & 0.8 & 2.0 \\
\hline
\end{tabular}

other health related problems. The data in Table I are based on responses to questions posed during the study interview regarding visual impairment. For the survey purposes visual impairment was defined as whether the subject experienced blindness in one or both eyes or had any other trouble seeing even when wearing glasses. Although this definition is vague, these data do provide one method of investigating the impact of ageing on self-reported visual status, and the results are consistent with other studies. According to this table, the prevalence of visual impairment increases with increasing age and is approximately two and a half times greater for males and females 75 years and older than for males and females between 45-64 years of age (e.g. the rate for males and females age 45-64 is $49.7 / 1,000$ and the rate for males and females age $\geqslant 75$ is $138.9 / 1,000)$. In other words, about one of seven individuals 75 years and older in the U.S. feel that they are visually impaired. ${ }^{10}$

The FES is a population based prevalence study conducted between 1973 and 1975 which provides data from comprehensive standardised ophthalmologic examinations performed on 2,631 persons aged 52-85 years who are or had been residents of Framingham, Massachusetts. This study group comprised two-thirds of the surviving members of the cohort who had participated in the Framingham Heart Study. The data on visual acuity collected during this study permit an evaluation of the change in visual acuity with age. As shown in Table II, the per cent prevalence of good vision (visual acuity of 20/20 20/25) decreases steadily with increasing age, with approximately a 20 per cent decrease between the ages of 52-65 years and 75 years and greater. On the other hand, the per cent prevalence of those with poor vision or visual acuity of $20 / 200$ or worse increases 8 -fold between the ages of 52-65 years and 65-74 years. The data also suggest that the frequency of being legally blind at age 75 years and older is 20 times as great as at ages 52-65 years, with two out of every 100 persons 75 years and older being legally blind. ${ }^{11}$

The data from the Blindness Registry in Oxford, the HIS, and the FES consistently demonstrate a definite increase in visual impairment and blindness with increasing age, with the most dramatic increases beginning about the age of 75 years..$^{3,10,11}$ These studies suggest that the risk of being visually impaired may increase as much as 20 times between middle age (50-65 years) and older age ( 75 years and older). While prevalence data on visual loss from developing countries are generally not as reliable as those from the United States and the United Kingdom, they do indicate an increase in visual impairment with increasing age. ${ }^{7,8}$

\section{Leading Causes of Visual Loss in the Elderly}

Table III shows that in blindness registries for

Table III. Leading causes of visual loss for selected countries with blindness registries (per cent)

\begin{tabular}{lcccc}
\hline & $\begin{array}{c}\text { England and } \\
\text { Wales } \\
1955-1962^{2}\end{array}$ & $\begin{array}{c}\text { United } \\
\text { States } \\
1970^{5} \\
\%\end{array}$ & $\begin{array}{c}\text { Canada } \\
1964^{6}\end{array}$ & $\begin{array}{c}\text { West of } \\
\text { Scotland } \\
1980^{4} \\
\%\end{array}$ \\
Cause & $\%$ & 13 & 5 & 30 \\
Age related macular degeneration & 26 & 16 & 15 & 10 \\
Cataract & 23 & 11 & 10 & 15 \\
Glaucoma & 12 & 11 & 5 & 8 \\
Diabetic retinopathy & 7 & 8,353 & 24,605 & 647 \\
Total registered blind & 60,309 & & \\
\hline
\end{tabular}


Table IV. Per cent prevalence of cataract of senile or undetermined aetiology by age and sex in Nepal blindness survey, $1981^{17}$

\begin{tabular}{lccccc}
\hline & \multicolumn{2}{c}{ Cataract prevalence (per cent) } \\
\cline { 2 - 3 } & \multicolumn{2}{c}{ Males } & & \multicolumn{2}{c}{ Females } \\
\cline { 2 - 3 } \cline { 5 - 6 } Age (years) & $N$ & $\%$ & & $N$ & $\%$ \\
\hline $60-64$ & 367 & 14 & & 446 & 25 \\
$65-69$ & 256 & 21 & & 248 & 37 \\
$70-74$ & 195 & 32 & & 171 & 48 \\
$\geqslant 75$ & 138 & 42 & & 117 & 56 \\
\hline
\end{tabular}

England and Wales, 1955-1962;2 United States, $1970 ;{ }^{5}$ Canada, $1964 ;{ }^{6}$ and the west of Scotland, $1980^{4}$ the leading causes of visual loss are age related macular degeneration (AMD), cataract, glaucoma, and diabetic retinopathy. The limitations of data from blindness registries must be kept in mind when interpreting these findings. These are that:

(1) the data only reflect those who register as legally blind;

(2) the proportion who register probably varies from one country to another; and

(3) the classification of the cause of blindness is not done in a standardised way.

These limitations obviously affect the accuracy of the data. However, these data may be useful in providing relative frequencies for causes of visual loss within each registry.

The tremendous variation in the percentage of persons who are blind from AMD among the different registries may be due, at least in part, to the varying diagnostic criteria used. However, it is also possible that the differences are real.

The decrease in the percentage of persons blind from cataract (from 23 per cent in England and Wales, 1955-1962, to 10 per cent in the west of Scotland in 1980) may reflect, at least in these countries, a dramatic increase in the number of cataract operations performed between 1962 and 1980. This decrease would probably not be as apparent in countries such as India where access to treatment is limited.

The proportion blind from glaucoma is relatively constant among the different studies. The proportion blind from diabetic retinopathy is similar for England and Wales, Canada, and the west of Scotland. It may be slightly higher in the United States because of the method of classifying these subjects. In contrast to these chronic and age related causes of blindness in western nations, many causes of blindness in African and Asian countries are infectious in origin, such as trachoma and onchocerciasis, and more younger people are affected..$^{9,15}$

\section{A. Cataract}

Cataract is the primary cause of blindness in 116 countries covered by the Blindness Data Bank which is a component of the WHO Programme for the Prevention of Blindness. It is estimated to cause severe loss of vision in $\mathbf{4 0 . 4}$ per cent of an estimated 42 million blind persons worldwide, with 13 million being in developing countries and 4 million being in developed countries. ${ }^{16}$ Because cataract is prevalent in developing as well as developed countries, it is the only ocular condition which is a leading blinding condition in all countries of the world. It is particularly prevalent in developing countries in the tropical areas and accounts for $30-50$ per cent of vision loss in various African countries not endemic for trachoma or onchocerciasis. ${ }^{16}$

While in certain areas of Asia and Africa cataract appears to have an earlier onset than in other places, all countries with available data show that prevalence increases with age. Table IV presents data collected as part of the Nepal Blindness Survey in 1981 on the prevalence of cataract of senile or undetermined aetiology by age and sex. For the purposes of this study, cataract cases were defined as persons diagnosed by an ophthalmologist to have lenticular opacities of undetermined cause in either or both eyes (incipient, immature, or mature cataracts) or as persons who were aphakic or had after-cataract membranes. These rates are based on a total of 956 males and 982 females over the age of 60; 138 males and 117 females were 75 years and older. Prevalence increases with increasing age; the increase is 3-fold for males and approximately double for females between the ages of 60-64 years and 75 years and older. These data show a consistently higher cataract prevalence for females than males in each age group, and beginning at the age group of $60-64$ years, 
one-quarter of the Nepalese women have some degree of cataract. By the age of 75 , more than half of the female population has developed cataracts. ${ }^{17}$

Table V allows a comparison between Nepal and the United States. This table presents data from the NHANES conducted during 1971-1973 on the per cent prevalence of cataracts by age, race, and sex. This study is based on a probability sample of the noninstitutionalised civilian U.S. population who received standardised ophthalmological examinations.

Cataract cases were evaluated by slit lamp and direct ophthalmoscope and were defined for this study as persons with aphakia or visual acuity of 20/25 or worse and any of the following conditions in either eye:

Immature cataract: minimal to moderate lens opacity in which transparent lens fibres are still present;

Intumescent cataract: swelling of lens due to inhibition of water;

Mature cataract: entire lens has become opaque;

Morgagnian cataract: cortex liquefied and nucleus settled.

The data indicate that cataract prevalence increases with age for white and black males and females with the frequency being higher in blacks than whites. Approximately 40 per cent of blacks and 21-27 per cent of whites aged $65-75$ in the U.S. have some vision loss from cataracts according to this study. ${ }^{18}$

Two drawbacks to this study are that

(1) only 70 per cent of the selected population received eye examinations; and

(2) assessment of the diagnoses may be unreliable because of the larger number of examiners with diverse levels of experience and training.

However, the NHANES data have provided the first national estimates for cataracts and other eye conditions and have proved to be useful as guidelines for prevalence estimates.

Leske and Sperduto have reviewed the epidemiology of senile cataract extensively. This paper will describe briefly their discussion of possible risk factors. ${ }^{19}$ There have been relatively few epidemiologic studies investigating risk factors for senile cataracts despite its high frequency. However, these studies have iden- tified a number of factors as being associated with senile cataracts or lens opacities, some of which have been identified more consistently than others. These factors, which are presented in Table VI, have been grouped into three categories of demographic factors, other host factors, and environmental factors. The demographic factors are age, sex, and geographic. The association of cataracts with increasing age has been consistently documented in numerous studies. Regarding sex or gender as a possible risk factor, blindness registry data in the U.S. ${ }^{5}$ and England ${ }^{2}$ have shown senile cataract blindness to be more common among women than men; prevalence studies in the U.S. (NHANES, ${ }^{18}$ FES $^{10}$ ), Scotland, ${ }^{4}$ and $\mathrm{Nepal}^{17}$ have also demonstrated cataracts to be more frequent among females. Studies on cataract prevalence conducted throughout the world have indicated tremendous variation in its frequency in different countries and in different regions within a country such as India, with cataracts being most common in developing countries in tropical areas. These variations in cataract frequency may be real and thus be due to genetic or environmental factors, or they may be artifactual due to differences in disease definitions, study methodology, and availability of medical services. ${ }^{19}$

The category of other host factors includes those of diabetes mellitus, high blood pressure, nutritional factors such as proteins, tryptophan and other essential amino acids, riboflavin, selenium, and calcium, and family cataract history. Of these factors, the association of cataracts and diabetes has been studied most extensively in hospital based surveys, as well as in the population based studies of NHANES and FES. The results of these studies tend to support the existence of such an association which seems to be stronger at younger ( $50-69$ years) than older ( $\geqslant 70$ years) ages. The hypothesis that inadequacy of certain nutritional factors contributes to the development of senile cataracts has not yet been documented by clinical or epidemiologic data. However, data from animal studies and some epidemiologic studies suggest a need for additional research in this area. ${ }^{19}$

The major environmental factors which have been suggested as possible risk factors 
Table V. Per cent prevalence of cataract by age, race, and sex: Health and Nutrition Examination Survey, $1971-1973^{18}$

\begin{tabular}{lcccc}
\hline & \multicolumn{4}{c}{ Age (years) } \\
\cline { 2 - 5 } & \multicolumn{2}{c}{$45-64$} & & $65-75$ \\
\cline { 2 - 5 } \cline { 5 - 5 } Sex and race & $N$ & $\begin{array}{c}\text { Prevalence } \\
\%\end{array}$ & & $\begin{array}{c}\text { Prevalence } \\
\%\end{array}$ \\
\hline White & & & & \\
$\quad$ Males & 531 & 5.6 & 612 & 21.6 \\
$\quad$ Females & 561 & 2.1 & 654 & 26.8 \\
Black & & & & \\
$\quad$ Males & 156 & 8.3 & 193 & 38.3 \\
$\quad$ Females & 165 & 8.5 & 184 & 39.1 \\
\hline
\end{tabular}

for senile cataracts are certain types of radiation including ionising, ultraviolet, infrared, and microwave and a variety of drugs with cataractogenic potential, such as corticosteroids and phenothiazines. (A possible protective role for aspirin is under study but data are inconclusive.$^{20}$ ) Of these factors, preliminary evidence suggests that ultraviolet radiation may increase the risk of cataracts but the data are still inconclusive. ${ }^{17}$ Additional studies are needed to investigate further each of these potential associations.

\section{B. Age Related Macular Degeneration}

Age related macular degeneration, also commonly called senile macular degeneration, poses a significant clinical and public health

Table VI. Possible risk factors for senile cataracts $^{19}$

Demographic factors
Age
Sex
Geographic
Other host factors
Diabetes mellitus
High blood pressure
Nutritional factors
Family cataract history
Environmental factors
Radiation
Ionising
Ultraviolet
Infrared
Microwave
Drugs (e.g. aspirin)

challenge as a leading cause of eye disease in the elderly, particularly in developed countries such as the United States, Canada, and the United Kingdom. The data from the two blindness registries in the United States, $1970^{5}$ and the west of Scotland, $1980,{ }^{4}$ presented in Table VII, indicate an increase in AMD blindness with increasing age, and each shows a similar incidence of blindness from AMD for each age group. This table indicates that of those persons 75 years and older who are blind, approximately half are blind due to AMD. Since, unlike cataracts, the treatment possibilities for most AMD patients are limited, the incidence of AMD blindness can only be expected to increase with the increasing numbers of individuals reaching older ages.

The NHANES study determined the estimated prevalence for AMD by age, race, and sex. These findings are presented in Table VIII and indicate an increase in prevalence with increasing age in both blacks and whites of both sexes. AMD was defined for the purposes of this study as:

Senile macular degeneration: loss of macular reflex pigment dispersion and clumping, and drusen associated with visual acuity of $20 / 25$ or worse believed to be due to this disease;

Senile disciform macular degeneration: choroidal haemorrhage and connectivetissue proliferation between retinal pigment epithelium and Bruch's membrane causing an elevation of the foveal retina (this condition should be differentiated from disciform degenerations of other causes, e.g. histoplasmosis, toxoplasmosis, angioid streaks, and high myopia);

Senile circinate macular degeneration: perimacular accumulation of lipoid material within the retina. ${ }^{18}$

In contrast to clinical impressions and studies that AMD is less frequent among black than whites, ${ }^{21,22}$ the NHANES results show that AMD prevalence is similar between blacks and whites. ${ }^{18}$ Additionally, this study found a similar prevalence of AMD between males and females. ${ }^{18}$ This finding differs from the observation in the Framingham Eye Study that AMD was approximately 50 per cent more prevalent in women than men in each of 
Table VII. Estimated per cent of blindness from age related macular degeneration by age in United States ${ }^{5}$ and Scotland ${ }^{4}$

\begin{tabular}{lccccc}
\hline & \multicolumn{2}{c}{ U.S., 1970} & & \multicolumn{2}{c}{ Scotland, 1980} \\
\cline { 2 - 5 } \cline { 5 - 6 } Age (years) & $N$ & $\begin{array}{c}\text { Per cent AMD } \\
\text { blindness }\end{array}$ & & $N$ & $\begin{array}{c}\text { Per cent AMD } \\
\text { blindness }\end{array}$ \\
\hline $45-64$ & 2,382 & 18 & 118 & 14 \\
$65-74$ & 1,266 & 28 & & 214 & 26 \\
$75-84$ & 1,551 & 47 & & 216 & 48 \\
$\geqslant 85$ & 733 & 61 & & 76 & 49 \\
\hline
\end{tabular}

Table VIII. Per cent prevalence of age related macular degeneration by age, race, and sex, NHANES, 1971$1973^{18}$

\begin{tabular}{|c|c|c|c|c|}
\hline \multirow[b]{3}{*}{ Sex and race } & \multicolumn{4}{|c|}{ Age (years) } \\
\hline & \multicolumn{2}{|c|}{$45-64$} & \multicolumn{2}{|c|}{$65-75$} \\
\hline & $N$ & $\begin{array}{c}\text { Prevalence } \\
\%\end{array}$ & $N$ & $\begin{array}{c}\text { Prevalence } \\
\%\end{array}$ \\
\hline \multicolumn{5}{|l|}{ White } \\
\hline Males & 531 & 2.3 & 612 & 9.6 \\
\hline Females & 561 & 2.3 & 654 & 6.9 \\
\hline \multicolumn{5}{|l|}{ Black } \\
\hline Males & 156 & 3.8 & 193 & 9.3 \\
\hline Females & 165 & 2.4 & 184 & 11.4 \\
\hline
\end{tabular}

Table IX. Possible risk or associated factors for age related macular degeneration

Demographic factors
Age
Sex
Race
Other host factors
High blood pressure
Cardiovascular disease history
Lung infection history
Left ventricular hypertrophy
Decreased vital capacity
Iris colour (blue or medium pigment)
Hyperopia
Decreased hand grip strength
Short height
Family AMD history
Dermal elastosis
Nutritional factor (e.g. vitamins E and C)
Environmental factors
Cigarettes
Chemicals
Sunlight

the age groups studied, ${ }^{11}$ but corroborates the finding of no increased prevalence of mild or more severe senile macular changes among females when compared to males.

When interpreting these data, one must keep in mind the drawbacks of this study which have been discussed previously. However, these results have raised doubts both about the observation in the FES that males are at lower risk of developing AMD than females and the clinical impression that blacks are at lower risk of developing this disease than whites. These observations require further study.

The information on possible risk factors for AMD presented in Table IX comes mainly from the FES, NHANES, and a number of case-control, clinical, and animal studies. These factors have been grouped for the purposes of the present discussion into the categories of demographic, other host, and environmental factors, which are the same used for the cataract discussion. The only factor consistently found to be associated with 
AMD in all studies is that of age. AMD prevalence increases with increasing age, and there is a rapid increase in prevalence among persons 65 years and older. ${ }^{11}$ As previously discussed, the question of whether being female $^{11}$ or being white ${ }^{21,22}$ increases the risk of developing AMD has been raised by several studies and requires further investigation.

Regarding other host factors, each of the following factors have been identified by one or more studies as being associated with AMD: high blood pressure, ${ }^{18,24-26}$ history of cardiovascular disease,${ }^{27}$ history of lung infection, ${ }^{24}$ left ventricular hypertrophy, ${ }^{24}$ decreased vital capacity, ${ }^{24}$ blue or medium pigmented iris colour, ${ }^{27,28}$ hyperopia, ${ }^{25,27,29}$ decreased hand grip strength, ${ }^{24,27}$ short height,${ }^{24}$ family history of $\mathrm{AMD},{ }^{27}$ dermal elastosis, ${ }^{30}$ and nutritional factors such as Vitamins E and C. ${ }^{31,32}$ Of these, high blood pressure, cardiovascular disease history, light or medium iris colour, hyperopia, decreased hand grip strength, family history of AMD, and certain nutritional factors appear most likely to be correlated with this condition.

The association between AMD and high systolic and diastolic blood pressure and hypertension history was found by the Framingham Eye Study in $1977 .{ }^{24}$ Further analyses of these data published recently by Sperduto and Hiller also showed a steady increase in the degree of this association with increased duration of hypertension, which raises the possibility that hypertension at an early age may increase AMD risk. ${ }^{33}$ The NHANES also identified a slightly higher mean systolic blood pressure for AMD cases than non-cases, although the statistical significance of this association was not consistent among all age-sex-race categories. ${ }^{18}$ One casecontrol study by Delaney and Oates of 50 cases and age-sex matched controls found an association between AMD and antihypertensive drug use ${ }^{25}$ another larger case-control study by Hyman et al. found no association between elevated blood pressure, hypertension history, or use of antihypertensives with AMD. However, they did find AMD to be associated with a history of one or more cardiovascular diseases, including arteriosclerosis, circulatory problems, hypertension, stroke and/or transient ischaemic attack, myocardial infarction, and angina. ${ }^{27}$ The findings of these different studies raise questions about the possibility of a relationship between AMD and hypertension and/or other cardiovascular diseases and the nature of such an association if it is real.

The suggestion that light iris pigmentation might be associated with an increased risk of developing AMD was initially suggested by the clinical observations that AMD may be less prevalent in blacks than whites. Two casecontrol studies-one by Hyman et al. ${ }^{27}$ and one by Weiter ${ }^{28}$ - have provided some data to suggest such an association. While the role that light iris pigmentation might play in the development and/or progression of AMD remains unclear, there is enough evidence to warrant further investigation of this possible association.

Hyperopia ${ }^{25,27,29}$ and decreased hand grip strength $^{24,27}$ have been identified as associated factors in at least two studies. The nature of the relationship between these factors and the development of AMD remains unclear and should be studied further.

Family AMD history was identified as a positive risk factor for AMD by the Hyman case-control study, with AMD cases demonstrating a three-fold excess risk of having AMD if a parent or sibling also had the disease. ${ }^{27}$

The environmental factors which have been suggested as possible risk factors for AMD are cigarettes, ${ }^{27}$ chemicals (e.g. occupational exposures), ${ }^{27}$ and prolonged exposure to sunlight. ${ }^{34}$ These factors have been suggested by epidemiologic and/or clinical studies and should be investigated further.

\section{Glaucoma}

Glaucoma is the third leading cause of eye disease among the elderly although the magnitude of its impact on blindness, particularly in individuals over 75 years, is much less than AMD. In black populations, however, the disease appears to be a major cause of blindness and presents at an earlier age. Glaucoma is the first cause of blindness in U.S. blacks, and registration for glaucoma blindness is eight times higher than in whites. ${ }^{5}$ The per cent of blindness due to glaucoma presented in Table $\mathrm{X}$ is approximately 15 per cent and 16 
Table X. Estimated per cent of blindness from glaucoma by age in United States ${ }^{5}$ and Scotland ${ }^{4}$

\begin{tabular}{lccccc}
\hline & \multicolumn{2}{c}{ U.S., 1970} & & \multicolumn{2}{c}{ Scotland, 1980} \\
\cline { 2 - 3 } \cline { 5 - 6 } Age (years) & $N$ & $\begin{array}{c}\text { Per cent glaucoma } \\
\text { blindness }\end{array}$ & & $N$ & $\begin{array}{c}\text { Per cent glaucoma } \\
\text { blindness }\end{array}$ \\
\hline $45-64$ & 2,382 & 13.3 & 118 & 12.7 \\
$65-74$ & 1,266 & 15.8 & 214 & 20.5 \\
$75-84$ & 1,551 & 14.8 & 216 & 16.2 \\
$\geqslant 85$ & 733 & 9.8 & 76 & 7.9 \\
\hline
\end{tabular}

per cent in individuals aged 75-84 and approximately 10 per cent and 8 per cent in individuals 85 years and older in the U.S. ${ }^{5}$ and Scotland studies, ${ }^{4}$ respectively. These percentages are compared with approximately 50 per cent of blindness due to AMD in the age categories. In both studies the per cent of blindness increases only slightly with age at the younger ages and then actually decreases in the oldest age groups. This decrease may be a real decrease due to glaucoma patients developing blindness from other reasons at older ages or may be artifactual due to problems of diagnosing glaucoma blindness, or registering as blind from glaucoma at older ages. However, since the results of both studies are consistent, there is a stronger possibility that the observation is real. Perhaps with recent advances in glaucoma treatment the impact of glaucoma as a major cause of severe visual impairment in the elderly is being reduced.

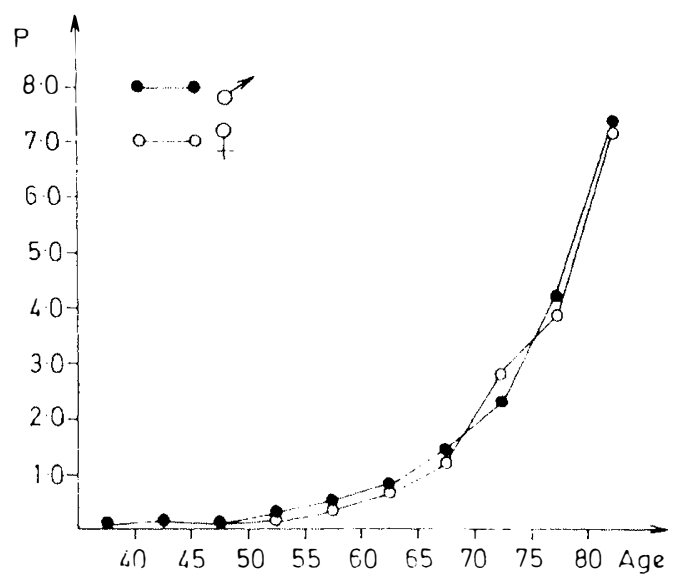

Fig. 2. Per cent prevalence of glaucoma, Gothenburg, Sweden, 1982.35
Even though blindness from glaucoma may decrease with age the per cent prevalence increases steadily with increasing age. Figure 2 presents data from a study in Gothenburg, Sweden in 1982 and demonstrates an increase from approximately 0.025 per cent prior to the age of 45 to more than 7 per cent by the age of 80 with the most dramatic increase in prevalence beginning between $65-70$ years. ${ }^{35}$ Because glaucoma was defined in this study as all residents in Gothenburg under treatment for glaucoma or on a check-up programme after glaucoma surgery in any ophthalmological practice or clinic, these results must be regarded cautiously. However, the finding of an increase in prevalence with increasing age was consistent with the observations of other studies such as the FES. ${ }^{11}$

Factors that have been suggested as possibly increasing the risk of glaucoma are summarised in Table XI. These include the demographic factors of older age, being male, being black, having certain occupations which are based primarily indoors or outdoors, or different geographical locations, and having a positive glaucoma family history. Of these age, male sex, and a positive glaucoma family history have been identified most consistently in different studies and seem most likely to be associated with an increased risk of glaucoma. Systemic factors of diabetes and blood pressure and ocular factors, including elevated intraocular pressure, enlarged cup/disc ratio, exfoliation syndrome, and high myopia, have also been investigated in numerous studies with varying results. Glaucoma field loss has been associated with high and low levels of blood pressure as well as a sudden decrease in blood pressure. The nature of this association is not well understood and requires further investigation. For further discussion of this 
Table XI. Possible risk factors for open angle glaucoma

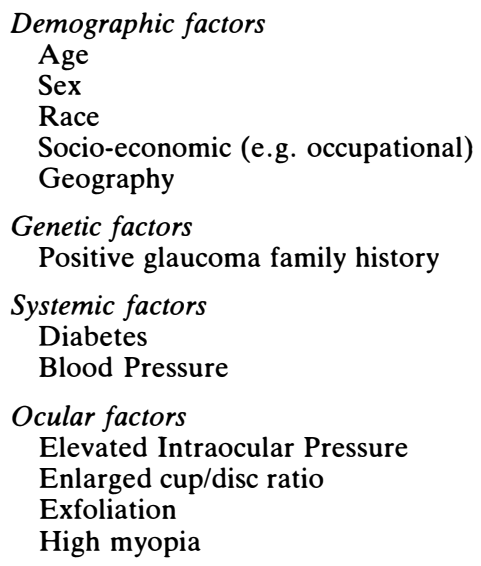

Table XII. Estimated per cent of blindness from diabetic retinopathy by age, Scotland, $1980^{4}$

\begin{tabular}{ccc}
\hline & & $\begin{array}{c}\text { Per cent diabetic } \\
\text { retinopathy } \\
\text { blindness }\end{array}$ \\
\hline $45-64$ & $N$ & 18.6 \\
$65-74$ & 118 & 8.9 \\
$75-84$ & 214 & 6.5 \\
\hline
\end{tabular}

relationship, as well as the possible relationship of glaucoma with the other suggested risk factors, the reader is referred to an extensive discussion in a review on the epidemiology of open angle glaucoma by Leske. ${ }^{36}$

\section{Diabetic Retinopathy}

Diabetic retinopathy accounts for 6.5 per cent of the blindness registrations in persons 75-84 years of age in Scotland in 1980 (Table XII). ${ }^{4}$ Even though over half of the patients who are blind from diabetic retinopathy are elderly, they represent a small percentage of the total elderly blind. It is less significant as a cause of visual loss among the elderly because the numbers of persons with other ocular diseases, particularly AMD and cataract, increase so dramatically with age. The FES demonstrated the prevalence of diabetic retinopathy to be 2,3 , and 7 per cent at ages of 52-64, 65-74, and 75-85 years, respectively, indicating that prevalence increases with age. ${ }^{11}$ Other epidemiologic studies of preva- lence and risk factors for diabetic retinopathy are described elsewhere and will not be discussed further. . $^{24}, 37-39$

\section{Summary and conclusions}

This discussion of the epidemiology of eye disease in the elderly has focused on describing the magnitude of the problem of vision loss in the elderly and summarising epidemiologic characteristics of the major causes of eye disease and vision loss. The available data on the prevalence of blindness and vision loss, although limited by variations in definitions of blindness and the diseases under study and problems in study design and execution, have consistently demonstrated that the prevalence of visual loss and blindness increases significantly with increasing age.

Cataract is the most prevalent eye disease in the elderly in the world and is a leading cause of visual loss in developing as well as in developed nations. The other major eye diseases in the elderly are AMD, glaucoma, and diabetic retinopathy. Since cataract, glaucoma, and to some extent diabetic retinopathy are treatable, efforts must be made throughout the world to increase access to treatment. While in the U.S. the number of cataract operations has increased dramatically in recent years, similar increases have yet to be seen in countries such as India where more than six million persons are blind from cataract. ${ }^{1}$ Since the numbers of individuals are increasing in the older age groups as more people are living longer, the prevalence of these eye diseases are expected to increase substantially. Table XIII presents the estimated and the projected per cent increase of cataracts and AMD in the United States between 1970 and 2030 for persons 55 years and older. ${ }^{40}$ These projections estimate almost 300 per cent increases for both of these conditions. Similar predictions were also made for glaucoma and diabetic retinopathy. ${ }^{40}$ These increasing numbers stress the need, not only for access to treatment, but for more efforts towards prevention, particularly for AMD where no long term treatment is available.

A number of risk factors have been suggested for cataract, AMD, and glaucoma and certain of these are similar, including age, hypertension, prolonged exposure to sun- 
Table XIII. Estimated prevalence* of selected eye diseases in the United States in 1970 and $2030 \dagger$ for men and women aged 55 and over ${ }^{40}$ (numbers in thousands)

\begin{tabular}{lrrr}
\hline & 1970 & 2030 & Per cent increase \\
\hline Cataract & & & \\
$\quad$ Both sexes & 5,389 & 14,799 & 275 \\
Men & 1,948 & 4,988 & 256 \\
Women & 3,441 & 9,811 & 285 \\
Senile macular degeneration & & & \\
$\quad$ Both sexes & 2,695 & 7,525 & 279 \\
Men & 907 & 2,417 & 266 \\
Women & 1,788 & 5,108 & 286 \\
\hline
\end{tabular}

* Prevalence estimates taken from Framingham eye study.

$\dagger$ Population estimates for 1970 and 2030 obtained from U.S. Department of Commerce Publications Series P-25, Number 519 and P-25, Number 704, respectively.

light, and nutritional factors such as Vitamin E. Additional studies are needed to define the risk factors for these different diseases with the goal of decreasing risk of disease and possible disease prevention.

Epidemiology can be extremely useful in accomplishing these goals as well as developing better estimates of the magnitude of the problem. Specific contributions can be made by:

(1) coordinating international studies with consistent diagnostic criteria to define more clearly the magnitude of the problems;

(2) conducting studies to determine risk factors with the goal of possible disease prevention; and

(3) conducting clinical trials to determine the best methods of treatment for these diseases in developing and developed countries.

Through the coordinated efforts of epidemiologists, clinicians, and other researchers, the goals of reducing the numbers of individuals with these eye diseases and others causing severe visual loss can begin to be achieved.

\section{References}

${ }^{1}$ Kupfer C: Worldwide prevention of blindness. Am. J. Ophthalmol. 1983; 96: 543-5.

${ }^{2}$ Sorsby A: Reports on public health and medical subjects. No. 114. London, Her Majesty's Stationery Office, 1966.

${ }^{3}$ Caird FI, Williamson J, eds: The Eye and its Disorders in the Elderly. Bristol, John Wright \& Sons Ltd, 1986; 3.
${ }^{4}$ Ghafour IM, Allan D, Foulds W: Common causes of blindness and visual handicap in the west of Scotland. Br. J. Ophthalmol. 1983; 67: 209-13.

${ }^{5}$ Kahn HA, Moorhead HB: Statistics on Blindness in the Model Reporting Area 1969-1970. Washington, USDHEW, PHS 1973; P.M. No. (NIH) $73-427$.

${ }^{6}$ Graham PA, Wallace J, Walsby E, et al.: Evaluation of postal detection of registrable blindness. Br.J. Prev. Soc. Med. 1968; 22: 238.

${ }^{7}$ Brilliant LB, Pokhrel RP, Grasset NC, et al.: Epidemiology of blindness in Nepal. Bull. WHO 1985; 63: 375-86.

${ }^{8}$ Maichuk YF: Epidemiology of blindness in the Middle East. Rev. Int. Trach. Pathol. Ocul. Trop. Subtrop. 1980; 57: 21-37.

${ }^{9}$ WHO Programme Advisory Group on the Prevention of Blindness: Data on blindness throughout the world. WHO Chronicle 1979; 33: 275-83.

${ }^{10}$ U.S. Department of Health and Human Services: Current estimates from the National Health Interview Survey, United States, 1983. Data from the National Heath Survey Series 10, No. 154. DHHS Publication No. (PHS) 86-1582. Hyattsville, 1986.

${ }^{11}$ Leibowitz HM, Krueger DE, Maunder LR, et al.: The Framingham Eye Study Monograph. Surv. Ophthalmol. 1980; 24 (Suppl): 335-610.

12 U.S. Department of Health, Education and Welfare: Plan and Operation of the Health and Nutrition Examination Survey. United States 19711973. National Center for Health Statistics, Vital and Health Statistics Series 1, No. 10a, 1973.

${ }^{13}$ Bjornsson G: Blindness in Iceland. A review of legally blind persons in Iceland 1 December 1979. Acta Ophthalmol. 1981; 59 921-27.

${ }^{14}$ Martinez GS, Campbell AJ, et al.: Prevalence of ocular disease in a population study of subjects 65 years old and older. Am. J. Ophthalmol. 1982; 94: 181-9.

${ }^{15}$ Kok PW: The epidemiology of trachoma blindness in Southern Africa. Soc. Sci. Med. 1983; 17: 1709-13.

${ }^{16}$ World Health Organization: Prevention of blind- 
ness. Cataract-a major blinding condition. Wkly Epidem. Rec. 1982; 57: 397-404.

${ }^{17}$ Brilliant LB, Grosset NC, Pokhrel RP, et al. : Association among cataract prevalence, sunlight hours, and altitude in the Himalayas. Am. J. Epidemiol. 1983; 118: 250-64.

${ }^{18}$ Klein BE, Klein R: Cataracts and macular degeneration in older Americans. Arch. Ophthalmol. 1982; 100: 571-3.

${ }^{19}$ Leske MC, Sperduto RD: The epidemiology of senile cataracts: a review. Am. J. Epidemiol. 1983; 118: 152-65.

${ }^{20}$ van Heyningen R, Harding JJ: Do aspirin-like analgesics protect against cataracts? Lancet 1986; 8490: 1111-13.

${ }^{21}$ Gregor Z, Joffe L: Senile macular changes in the black African. Br. J. Ophthalmol. 1978; 62: $547-$ 50.

${ }^{22}$ Chumbley LC: Impressions of eye diseases among Rhodesian blacks in Mashonaland. S. Afr. Med. J. 1977; 52: 316-8.

${ }^{23}$ Sperduto RD, Seigel D: Senile lens and senile macular changes in a population-based sample. Am.J. Ophthalmol. 1980; 90: 86-91.

${ }^{24}$ Kahn HA, Leibowitz HM, Ganley JP, et al.: The Framingham Eye Study. II. Association of ophthalmic pathology with single variables previously measured in the Framingham Heart Study. Am. J. Epidemiol. 1977; 106: 33-41.

${ }^{25}$ Delaney WV, Oates RP: Senile macular degeneration: a preliminary study. Ann. Ophthalmol. 1982; 14: 21-4.

26 Vidaurri J, Pe'er J, Halfon S-T, et al.: Association between drusen and some of the risk factors for coronary artery disease. Ophthalmol. 1984; 188: 243-7.

${ }^{27}$ Hyman LG, Lilienfeld AM, Ferris FL III, et al. Senile macular degeneration: a case-control study. Am. J. Epidemiol. 1983; 118: 213-27.

${ }^{28}$ Weiter J, Delori F, Wing G, Fitch K: Relationship of senile macular degeneration to ocular pigmentation. Am. J. Ophthalmol. 1985; 99: 185-7.

${ }^{29}$ Maltzman BA, Mullvihill MN, Greenbaum A:
Senile macular degeneration and risk factors: a case-control study. Ann. Ophthalmol. 1979; 11: 1197-201

${ }^{30}$ Blumenkranz MS, Russell SR, Robey MG, et al.: Risk factors in age-related maculopathy complicated by choroidal neovascularization. Ophthalmol. 1986; 93: 552-58.

${ }^{31}$ Hayes K: Retinal degenerations in monkeys induced by deficiencies of vitamin $\mathrm{E}$ or $\mathrm{A}$. Invest. Ophthalmol. 1974; 13: 499-510.

${ }^{32}$ Katz M, Parker K, Handelman G, et al.: Effects of antioxidant nutrient deficiency on the retina and retinal pigment epithelium of albino rats; a light and electron microscopic study. Exp. Eye Res. 1982; 34: 339-69.

${ }^{33}$ Sperduto RD, Hiller R: Systemic hypertension and age-related maculopathy in the Framingham Study. Arch. Ophthalmol. 1986; 104: 216-19.

${ }^{34}$ Mainster MA: Solar retinitis, photic maculopathy and the pseudophakic eye. Am. Intra-ocular Impl. Soc.J. 1978; 4: 84-6.

${ }^{35}$ Popovic V: The glaucoma population in Gothenburg. Acta Ophthalmol. 1982; 60: 745-58.

${ }^{36}$ Leske MC: The epidemiology of open-angle glaucoma: a review. Am. J. Epidemiol. 1983; 118: $166-91$.

${ }^{37}$ Klein R, Klein BEK, Moss S, et al.: The Wisconsin epidemiologic study of diabetic retinopathy. III. Prevalence and risk of diabetic retinopathy when age at diagnosis is 30 or more years. Arch. Ophthalmol. 1984; 102: 527-32.

${ }_{38}$ Caird FI, Pirie A, Ramsell TG: Diabetes and the Eye. Oxford, Blackwell Scientific Publications, 1969.

${ }^{39}$ Dwyer MS, Melton J III, Ballard DJ, et al.: Incidence of diabetic retinopathy and blindness: a population-based study in Rochester, Minnesota. Diabetes Care 1985; 8: 316-22.

${ }^{40} \mathrm{Kupfer}$ C: Tomorrow's blind population. In: World Blindness and its Prevention. Edited by the International Agency for the Prevention of Blindness under the direction of Sir John Wilson. London, Oxford University Press, 1980; 33. 